\title{
Medobčinsko sodelovanje kot mehanizem celostnega upravljanja razvoja in vstopanja $v$ čezmejna sodelovanja
}

UDK: 352.341 .232

\author{
Roman Lavtar \\ Služba Vlade Republike Slovenije za lokalno \\ samoupravo in regionalno politiko \\ roman.lavtar@gov.si
}

\begin{abstract}
IZVLEČEK
Prispevek obravnava oblikovanje zveze občin kot vzvoda za boljše medobčinsko sodelovanje pri uresničevanju razvojnih potreb občin oziroma kot načina predstavljanja interesov več občin pri opravljanju javnih služb na eni strani in kot način vključevanja skupine občin v čezmejno sodelovanje na drugi strani. Medobčinsko sodelovanje postaja razvojna nujnost slovenskih občin. Zapiranje v lastne meje ne rešuje obstoječih občinskih problemov, prej jih poglablja ali povzroča nove. Še posebej to velja za obmejne občine. Slovenska zakonodaja ponuja paleto pravno-formalnih možnosti sodelovanja med občinami. Za medobčinsko sodelovanje torej ni nobenih pravnih ovir, razen tistih v glavah nosilcev politične oblasti na lokalni ravni. Zakonodaja odpira možnosti sodelovanja tako za opravljanje upravnih nalog občin kot tudi za izvajanje javnih služb, tako gospodarskih kot negospodarskih. Zaradi boljše ponazoritve poskuša prispevek na konkretnem primeru za enajst pomurskih občin predstaviti prednosti ustanovitve zveze občin kot formalne oblike za učinkovitejše sodelovanje pri upravljanju Krajinskega parka Goričko in pri upravljanju bodočega trilateralnega parka $v$ sodelovanju z lokalnimi skupnostmi na drugi strani meje z Avstrijo in Madžarsko, pri čemer se kažejo potencialne možnosti ustanovitve evroregije na tem območju.
\end{abstract}

Ključne besede: lokalna samouprava, medobčinsko sodelovanje, čezmejno sodelovanje, evroregije, zveza občin.

\section{Uvod}

Prvotno zastavljeni cilj slovenske vlade, da ob uvedbi lokalne samouprave $\checkmark$ Republiki Sloveniji sredi devetdesetih let prejšnjega stoletja uvede koncept srednje velikih občin s približno stotnijo in pol občin, pri čemer nobena ne bi bila manjša od 5000 prebivalcev, je kmalu spodletel. Politični pritisk za ustanovitev novih občin je prevladal z ustanovitvijo novih občin v letih 1998 in 2002. 
Roman Lavtar

Medobčinsko sodelovanje kot mehanizem celostnega

Upravljanja razvoja in vstopanja $v$ čezmejna sodelovanja

Še danes nimamo zanesljivega odgovora na vprašanje, ali je teritorialna reforma slovenske lokalne samouprave sploh že končana. Tako lahko ugotovimo, da je Slovenija država z večjim številom manjših občin. Povprečna slovenska občina sicer šteje nekaj čez 10.000 prebivalcev, toda vsaka druga je manjša od 5.000 prebivalcev, kar petina jih je manjših od 3.000 prebivalcev. Podrobnejši pogled na zemljevid pa nam pokaže še strukturno težavo, saj je mreža občin vzhodne polovice države dvakrat gostejša od zahodne. Nerazvitost očitno povzroča med prebivalci več zanimanja za lastno občino.

Do prednosti ali slabosti večjega ali manjšega števila občin se ni mogoče vrednostno opredeljevati, ne da bi se prej odločili za kriterij. Evropski zgledi tu prav nič ne pomagajo, saj skandinavske države prisegajo na model velikih občin, srednja in južna Evropa pa na model majhnih občin. Prav gotovo so snovalci mreže občin $\vee$ vsaki državi poleg političnih, funkcionalnih in prebivalstvenih kriterijev upoštevali še mnoge druge, na primer zgodovinske, obmejne ali gorske. Funkcionalni kriterij - se pravi opredelitev nalog in pristojnosti občin - pa gre $v$ prid večjim občinam. Če imajo torej občine relativno veliko število zahtevnih nalog in pristojnosti, naj bi bile posledično po številu prebivalcev velike. Toda po drugi strani ne moremo spregledati dejstva, da imajo majhne občine prednost, ko gre za participacijo prebivalcev pri odločanju $\vee$ lokalnih javnih zadevah. Ob primerjavi nalog in pristojnosti slovenske občine z njeno velikostjo prav gotovo lahko ugotovimo, da velikost slovenske občine ni optimalna, ekonomski kriterij racionalnosti pa temu pritrjuje. Toda na zmanjšanje števila občin realno ni mogoče računati, kratkoročno tudi ne na ustanovitev druge ravni lokalne samouprave (pokrajin). Zato je odgovornost države in občin, da v največji možni meri poiščejo načine, s katerimi bodo nadomestili domnevno pomanjkljivost zaradi svoje majhnosti. Slovenska zakonodaja pozna instrumente, s katerimi je mogoče delno ali $\vee$ celoti nadomestiti morebitni primanjkljaj zaradi manjšega števila prebivalcev.

Opozoriti velja, da za medobčinsko sodelovanje velikost občine ni edini motiv. Pri pregledu dosedanjih izkušenj občin ugotovimo, da so $v$ medobčinsko sodelovanje vključene tudi večje občine $v$ grozdu $z$ manjšimi ali da sodelujeta dve enako veliki občini, ki po številu prebivalcev nikakor nista majhni. Žal natančne evidence ni, saj občine niso dolžne tovrstnih aktivnosti sporočati državnim organom, reprezentativni združenji pa tudi nimata zanesljivih podatkov. Ocenjujemo, da $\vee$ takšni ali drugačni obliki sodeluje kakih 30 slovenskih občin, kar je še vedno relativno majhno število, saj je to slaba sedmina vseh slovenskih občin. ${ }^{1}$

1 Izobraževalni posvet Zveze tajnikov slovenskih občin, ZTSO, Mestna občina Velenje, 23. november 2004 


\section{Roman Lavtar \\ Medobčinsko sodelovanje kot mehanizem celostnega Upravljanja razvoja in vstopanja $v$ čezmejna sodelovanja}

Namen prispevka je na konkretnem primeru prikazati formalne možnosti sodelovanja med občinami znotraj meja Republike Slovenije kot tudi pravne okvire sodelovanja skupine občin pri čezmejnem sodelovanju ob morebitni ustanovitvi evroregije.

\section{Oblike medobčinskega sodelovanja}

Zavedajoč se funkcionalne pomanjkljivosti majhnih občin se države na različne načine lotevajo normativnega reševanja omenjene težave. Nekatere, kot na primer Češka, so uvedle poli-tipski sistem občin, se pravi občin z različnim obsegom nalog in pristojnosti tako, da so večje občine $v$ grozdu skupaj $z$ manjšimi prevzele določene naloge tudi za prebivalce preostalih občin. ${ }^{2}$ Druge so zapovedale skupne občinske uprave za vse občine z manjšim številom prebivalcev. Tako na Bavarskem občina ne more imeti samostojne občinske uprave, če nima določenega števila prebivalcev. Hkrati pa imajo občine možnost ustanoviti t.i. aglomeracijsko skupnost (zvezo), ki mora imeti najmanj 50.000 prebivalcev. ${ }^{3}$ Gre za osebo javnega prava, ustanovljeno za potrebe medobčinskega sodelovanja na področju gospodarskega razvoja, urejanja prostora, stanovanjske politike in odpadkov. Tudi Francija pozna ureditev, ki neposredno vzpodbuja povezovanje občin $v$ aglomeracije (zveze), kjer tako ustanovljena nova samostojna pravna oseba opravlja javno službo za več občin ustanoviteljic. ${ }^{4}$

Slovenski parlament je uzakonil več rešitev, ki omogočajo tako opravljanje skupnih upravnih nalog kot tudi opravljanje skupnih javnih gospodarskih in negospodarskih služb. Občine lahko sodelujejo pri opravljanju upravnih nalog tako, da ustanovijo organ skupne občinske uprave, ki za vse občine ustanoviteljice opravlja določene upravne naloge. ${ }^{\boldsymbol{5}}$ Najbolj tipičen in najpogostejši primer je skupna inšpekcija ali redarstvo, občine pa se odločajo še za sodelovanje na področju urbanizma oziroma upravljanja s prostorom. Dve ali več občin z odlokom ustanovijo organ skupne občinske uprave, določijo sistemizacijo delovnih mest in predstojnika ter razmerje pri delitvi stroškov po številu prebivalcev. Skupni občinski (medobčinski) inšpektor tako izda prvostopenjsko odločbo, pritožbeni organ pa je župan tiste občine, na ozemlju katere je bila kršitev predpisa

2 Več o tem v Lavtar, R.: Primer uspešne regionalizacije, Reforma lokalne samouprave na Češkem, Slovenska uprava, str. 32-33, izd. Ministrstvo za notranje zadeve, štev. 3, letnik 4,

3 Zakon Svobodne dežele Bavarske z oznako NOR:INTX98001135L, ki se uporablja od 1.januarja 2002

4 Structure and operation of local and regional democracy, France, Council of Europe, Strassbourg, Prva formalizacija medobčinskega povezovanja v Republiki Franciji datira v davno leto 1890, ko je bil 22. marca sprejet zakon, ki je uredil možnost sodelovanja občin pri zagotavljanju javnih služb.

5 Zakon o lokalni samoupravi, 49.a člen 
Roman Lavtar

Medobčinsko sodelovanje kot mehanizem celostnega

Upravljanja razvoja in vstopanja $v$ čezmejna sodelovanja

ugotovljena. Občine se po enakem postopku lahko dogovorijo, da občinska uprava ene občine opravlja upravne naloge za vse druge občine.

Pri izvajanju javnih služb pa je mogoče medobčinsko sodelovanje formalizirati na dva načina. Prvi je soustanoviteljstvo javnih zavodov in javnih podjetij, drugi pa zveza občin. Dve ali več občin lahko zaradi gospodarnejšega in učinkovitejšega zagotavljanja javnih služb skupaj ustanovijo javni zavod ali javno podjetje.

Pri soustanoviteljstvu za izvrševanje ustanoviteljskih pravic in za usklajevanje odločitev občin $\vee$ zvezi z zagotavljanjem javne službe lahko občinski sveti občin soustanoviteljic ustanovijo skupni organ, ki ga sestavljajo župani. ${ }^{\boldsymbol{6}}$ Akt o ustanovitvi takega skupnega organa mora določati naloge organa, organizacijo dela organa in način sprejemanja odločitev, financiranje in delitev stroškov med občinami ustanoviteljicami. Tak skupni organ opravlja svoje naloge $v$ imenu in za račun občin, ki so ga ustanovile, sedež organa je v občini, kjer je sedež javnega zavoda ali podjetja, strokovne naloge za skupni organ pa opravlja občinska uprava občine, v kateri je njegov sedež.

Podrobnejša analiza delovanja skupnih organov občinske uprave in uresničevanja ustanoviteljskih pravic prek skupnih organov upravljanja pokaže, da s temi oblikami ni mogoče $v$ celoti uresničevati medobčinskega sodelovanja. To predvsem velja za sodelovanje pri izgradnji infrastrukture, pri izvajanju razvojnih programov in programov varstva naravne in kulturne dediščine ter varstva okolja. Problem so tudi investicije $\vee$ komunalno infrastrukturo večjega obsega, saj obstoječa pravila posameznim občinam zaradi majhnosti onemogočajo konkuriranje za pridobitev razvojnih sredstev. Deloma je sicer mogoče vrzel zapolniti s pogodbenimi razmerji med občinami, toda pomanjkljivost takšnih razmerij se kaže predvsem $v$ počasnosti in zahtevnih postopkih pri sprejemanju odločitev (sprejemanje identičnih dokumentov na dveh ali več občinskih svetih itd.) in pri izključenosti prebivalcev $\vee$ procesu sprejemanja odločitev. Za skupno izvajanje tudi nekaterih t.i. regulatornih pristojnosti, ki se nanašajo na odločanje o razvojnih vprašanjih, o uporabi prostora, določanju podrobnejših pogojev, cenah in drugih pogojih izvajanja javnih služb je potrebno medobčinsko sodelovanje zasnovati na drugačni pravni obliki. Ustanoviti je treba interesno zvezo občin ( $v$ nadaljevanju zveza občin).

\subsection{Zveza občin}

Evropska listina lokalne samouprave $v$ 10. členu opredeljuje pravico lokalnih skupnosti do združevanja za izvajanje svojih pooblastil, kjer z oblikovanjem konzorcijev z drugimi lokalnimi skupnostmi izvajajo naloge skupnega pomena.

6 Zakon o lokalni samoupravi, tretji in četrti odstavek 61. člena. 
Zakon o lokalni samoupravi tak konzorcij (ali aglomeracijo) poimenuje zveza občin. Zveza občin ni posebna lokalna skupnost, ni institucija nad občino, ampak mehanizem za skupno izvajanje občinskih nalog. Zveza občin se od prej opisanih oblik sodelovanja razlikuje po tem, da gre za ustanovitev nove samostojne pravne osebe javnega prava, ki ima za upravljanje ustanovljen svet zveze. Tako Zakon o lokalni samoupravi omogoča dvema ali več občinam, da zaradi skupnega urejanja in izvajanja posameznih upravnih nalog ter zaradi izvajanja skupnih razvojnih in investicijskih programov ustanovi eno-namensko ali večnamensko interesno zvezo ( $v$ nadaljevanju zvezo občin). Svet sestavljajo predstavniki občin ustanoviteljic in ima lahko tudi izvršilni organ ter lastno upravo. Zveza je kot organizacijska in pravna oblika zelo primerna za izpeljavo skupnih dolgoročnih projektov, ki presegajo občinske meje. Tako bi jo bilo primerno ustanoviti pri zagotavljanju pitne vode, pri organiziranju odlagališč komunalnih odpadkov pa tudi za upravljanje skupnih projektov, kakršen je na primer razvoj območja Krajinskega parka Goričko ali trideželnega parka, kar bomo podrobneje obravnavali v nadaljevanju. $\vee$ Sloveniji občine doslej niso ustanovile še nobene zveze. $^{8}$

Akt o ustanovitvi zveze občin mora vsebovati določbe o:

- namenu ustanovitve,

- nalogah zveze,

- statusnih določbah,

- načinu upravljanja zveze,

- premoženju in financiranju ter

- začetku delovanja in prenehanju zveze.

Namen ustanovitve je skupno urejanje in izvajanje nalog občin, ki se v zvezo povezujejo, in sicer upravnih nalog (regulatornih, servisnih nalog ali odločanja o upravnih stvareh) ter skupnih razvojnih in skupnih investicijskih programov. $Z$ ustanovitvijo je treba pri nalogah določiti tudi obseg prenosa občinskih nalog na zvezo in medsebojno razmerje med organi občin in zveze. Akt o ustanovitvi zveze predložijo ustanovitelji $\vee$ hrambo ministrstvu, pristojnemu za lokalno samoupravo, zahtevi za hrambo akta o ustanovitvi pa župani občin priložijo še sklepe občinskih svetov, s katerimi je bil akt sprejet. Župani objavijo odločbo in

$\mathbf{7}$ Zakon o lokalni samoupravi, 86. člen

8 Zato bi bila namera 11 pomurskih občin, da ustanovijo zvezo za skupno sodelovanje pri upravljanju Krajinskega parka Goričko, prvi primer formalizirane zveze občin. Zanimivo, da se poleg tega na območju Pomurja predstavniki 19 občin (nekatere občine sodelujejo $v$ obeh projektih) dogovarjajo z ministrstvom, pristojnim za okolje in prostor, za skupno ureditev oskrbe s pitno vodo. Tudi v tem primeru bi bila zveza občin najprimernejša oblika za izvedbo projekta in kasneje samega upravljanja oskrbe z vodo. 
Roman Lavtar

Medobčinsko sodelovanje kot mehanizem celostnega

Upravljanja razvoja in vstopanja $v$ čezmejna sodelovanja

ustanovni akt v Uradnem listu Republike Slovenije. Z dnem objave pridobi zveza status osebe javnega prava. ${ }^{{ }^{\circ}}$

\section{Vloga zveze občin}

\subsection{Ustanovitev zveze občin na območju Krajinskega parka Goričko}

Na pobudo Ministrstva za okolje in prostor $v$ sodelovanju z občinami z Goričkega v Prekmurju je Vlada Republike Slovenije jeseni 2003 sprejela uredbo, s katero je na podlagi Zakona o ohranjanju narave ustanovila Krajinski park Goričko. Ker ima ustanovitev parka ambicijo povezovanja gospodarskega razvoja in čezmejnega sodelovanja, kar je sicer tudi v pristojnosti izvoljenih predstavnikov lokalnih oblasti, nas je predvsem zanimalo, na kakšen način bi bilo mogoče z ustanovitvijo zveze občin interesno povezati občine, ki delujejo na območju parka. Interesna povezanost seveda ne pomeni unifikacije oziroma nasilnega poenotenja razvojnih načrtov, ampak predvsem povečanje učinkovitega in čim skladnejšega ravnanja občin pri odločanju o razvojnih prioritetah in $v$ konkretnem primeru tudi pri čezmejnem sodelovanju.

Sodelovanje občin na območju Krajinskega parka Goričko si ni mogoče predstavljati brez dogovora občin o načinu sodelovanja, ki bi skrajšal postopke in naredil vpliv občin na razvoj in dogajanje v parku ustrezno učinkovit. Predstavljajmo si, kako dolgo bo trajalo, da bodo identični dokumenti obravnavani in sprejeti na sejah enajstih občinskih svetov. Vztrajanje na opisanem načinu bo prej zaviralo kot spodbujalo izvedbo projektov $v$ parku.

Ustanovitev Krajinskega parka Goričko je ponovno sprožila vprašanje o načinu vključevanja občin ${ }^{10}$ pri procesu dolgoročnega razvoja širšega dela Pomurja. Zato bi morale vključene občine poskrbeti za uveljavitev lastnih interesov glede gospodarskega razvoja in ohranitve naravne in kulturne dediščine ter uskladitve teh interesov z interesi drugih občin znotraj območja parka. Upravljanje tako kompleksnega projekta kot je sonaravni in ekonomski razvoj dobre polovice Pomurja zahteva tesno medobčinsko sodelovanje, zato je razmislek o zvezi občin prav gotovo utemeljen. Prva evidentirana pobuda za ustanovitev zveze sega že v december 2003, toda do njene ustanovitve se zdi enako daleč kot pred letom

9 Zakon o lokalni samoupravi, 86. člen, tretji odstavek

$10 \mathrm{~V}$ svetu zavoda $\mathrm{v}$ skladu $\mathrm{z}$ določbami akta o ustanovitvi javnega zavoda sodelujejo poleg šestih predstavnikov Vlade Republike Slovenije, enega predstavnika nevladnega sektorja in enega zaposlenega trije predstavniki občin. Slednji predstavljajo interese enajstih občin. 
in pol. Zaenkrat politični nosilci oblasti očitno še niso našli dovolj razlogov in prave motivacije za usodni korak.

Formalni postopek ustanovitve zveze občin smo že podrobno obravnavali, poglejmo še, kakšno bi lahko bilo delovanje zveze $v$ svetu zveze in njegovih delovnih telesih. Po zgledu na oblikovanje občinskega sveta in njegovih stalnih ali začasnih delovnih teles bi lahko podobna posvetovalna telesa ustanovil tudi svet zveze. Opozarjamo pa, da razvejana organizacija zveze na začetku ni nujna, še več, zaradi morebitnega prevelikega števila teles bi lahko postala ovira za delovanje. Z delovanjem in razvojem zveze občin pa bi prej ali slej prišlo do potrebe po delitvi dela. Tako bi bilo treba razmisliti o bolj razvejani upravljavski infrastrukturi. Nekateri tuji zgledi, ki delujejo že vrsto let, priporočajo postopno ustanovitev specializiranih delovnih teles. Svet zveze občin bi tako ustanovil še komisije na primer za infrastrukturo, za podjetništvo, varstvo okolja, razvoj človeških virov, preprečevanje socialne izključenosti itd.

\section{Slika 1: Predlog organizacijske sheme zveze občin}

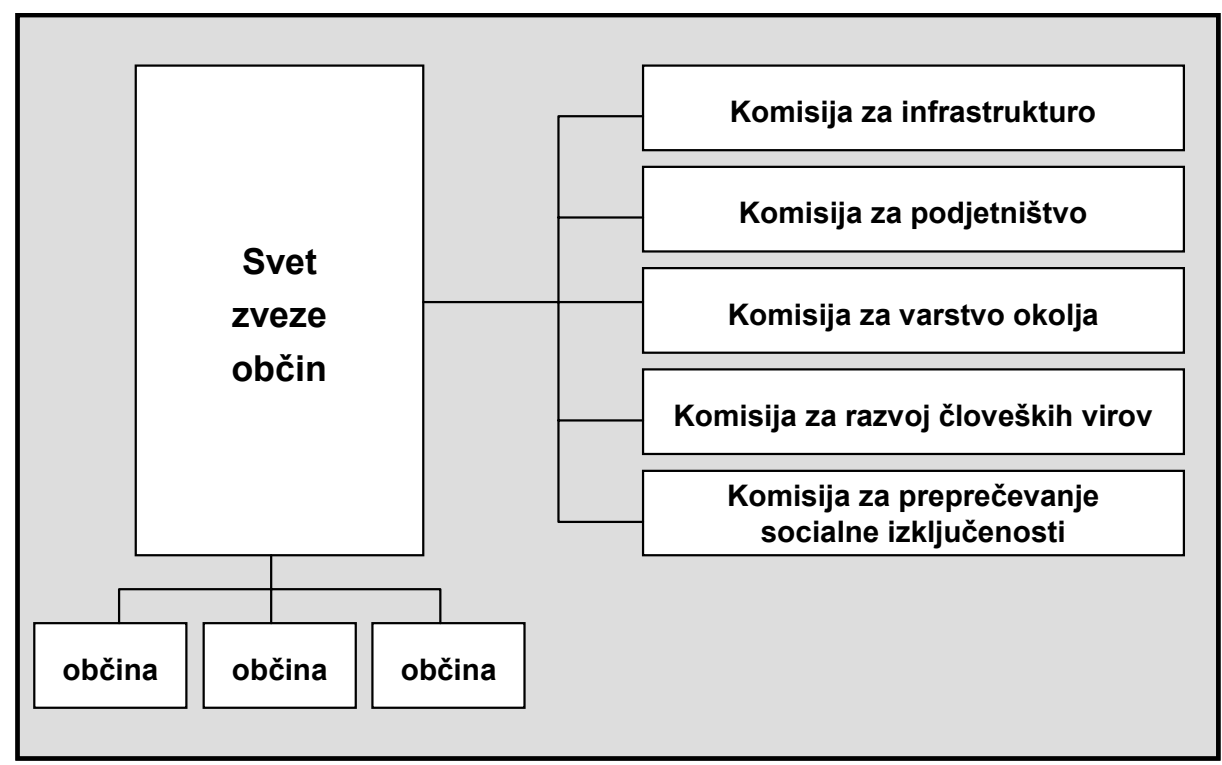

Sodelovanje prebivalcev pri odločanju $v$ javnih zadevah na lokalni ravni je pomembno za povečanje zaupanja $\vee$ lokalne oblasti in stopnje legitimnosti lokalne oblasti. Zato je priporočljivo $v$ delovanju občin nasploh pa tudi $\vee$ medobčinskem sodelovanju, $v$ upravljavske strukture oziroma procese odločanja vključiti predstavnike lokalnega prebivalstva in nevladnih organizacij, ki niso bili izvoljeni $v$ občinske svete občin ustanoviteljic zveze občin. Tako je treba pri morebitni ustanovitvi zveze občin ustanoviti posvetovalno telo, $v$ katerega so 
Roman Lavtar

Medobčinsko sodelovanje kot mehanizem celostnega

Upravljanja razvoja in vstopanja $v$ čezmejna sodelovanja

vključeni predstavniki okoljskih in interesnih združenj. Sodelovanje prebivalcev pri odločanju o javnih zadevah na lokalni ravni je prepogosto spregledana priložnost za upravljavce in nosilce javnih funkcij. Sodelovanje prebivalcev in nevladnega sektorja pri upravljanju in razvoju celotnega območja krajinskega parka pa bi bilo mogoče zagotoviti z vzpostavitvijo posvetovalnega telesa pri zvezi občin. Zakon tega izrecno sicer ne predpisuje, ne postavlja pa nobene ovire, ki bi onemogočala njegovo konstituiranje.

Vključitev nevladnih organizacij oziroma prebivalcev $v$ upravljanje samega krajinskega parka je ustanovitelj navidezno zagotovil z vključitvijo enega predstavnika $\checkmark$ svet zavoda. En sam predstavnik nevladnih organizacij $\vee$ svetu zavoda KP Goričko ne more zagotavljati realnega vpliva nevladnih organizacij tega dela Pomurja. Zato bi veljalo razmisliti o dodatnem posvetovalnem telesu, sestavljenem iz predstavnikov naravovarstvenih, okoljskih in drugih organizacij, ki združujejo ekonomske dejavnike (pridelovalce sadja, turistične kmetije, ...) pri zvezi občin.

\subsection{Zveza občin in čezmejno sodelovanje}

Že omenjeni 10. člen Evropske listine lokalne samouprave določa tudi pravico lokalnih skupnosti do mednarodnega sodelovanja, seveda pod pogoji, določenimi $\vee$ Zakonu o lokalni samoupravi, ki podrobneje opredeljuje citirani člen iz evropske listine. Poleg tega je dodatna pravna podlaga za mednarodno, še posebej čezmejno sodelovanje slovenskih občin pred 25 leti podpisana Evropska okvirna konvencija o čezmejnem sodelovanju teritorialnih skupnosti ali oblasti, znana tudi kot madridska, ki jo je Republika Slovenija ratificirala v letu $2003^{11}$. Konvencija ima še dva protokola kot dodatka za lažjo izvedbo čezmejnega sodelovanja, tretji pa je $v$ pripravi.

Odkar obstajajo državne meje, se lokalne skupnosti soočajo s težavami. Omejeno gibanje, oteženo reševanje vsakodnevnih problemov prebivalcev (oskrba s pitno vodo, dnevna migracija zaposlenih, obdelovanje kmetijskih zemljišč itd.) in omejene pravice lokalnih skupnosti pri mednarodnem sodelovanju so vir resnih preizkušenj lokalnih skupnosti. Pravzaprav je povojna politika zahodnoevropskih držav $\vee$ težnji po sodelovanju docela spremenila razumevanje državne meje iz črte, ki razdvaja, $\vee$ črto, ki povezuje. Ustanovitev Evropske unije in dogovor o prostem pretoku oseb in kapitala $\vee$ Evropi pa je pomembno pospešila čezmejno sodelovanje občin in regij. S širjenjem evropskih integracijskih procesov se ta problem zmanjšuje, toda sam od sebe ne izginja. Lokalne skupnosti, še posebej

11 Zakon o ratifikaciji Evropske okvirne konvencije o čezmejnem sodelovanju teritorialnih skupnosti ali oblasti (MEOKČS), Ur. List RS, MP št. 8/2003 
$\checkmark$ novih desetih državah članicah, ki niso vajene čezmejnega sodelovanja, imajo tudi v novih okoliščinah lahko resne težave. Spričo razvejanih možnosti sofinanciranja čezmejnega sodelovanja med državami članicami iz različnih virov EU pa lahko obmejne občine to okoliščino izkoristijo za hitrejši razvoj in odpravo ovir, ki jih povzroča državna meja.

Predstavljajmo si sodelovanje slovenskih občin s občinami iz sosednjih občin Avstrije in Madžarske po klasični poti prek zunanjih ministrstev. Spodnja slika pokaže vso zapletenost, dolgotrajnost in popolno nefunkcionalnost pri klasični poti reševanja akutnih problemov, ki zadevajo razvojne prioritete občin $\checkmark$ vseh treh državah.

Slika 2: Klasična pot sodelovanja obmejnih občin*

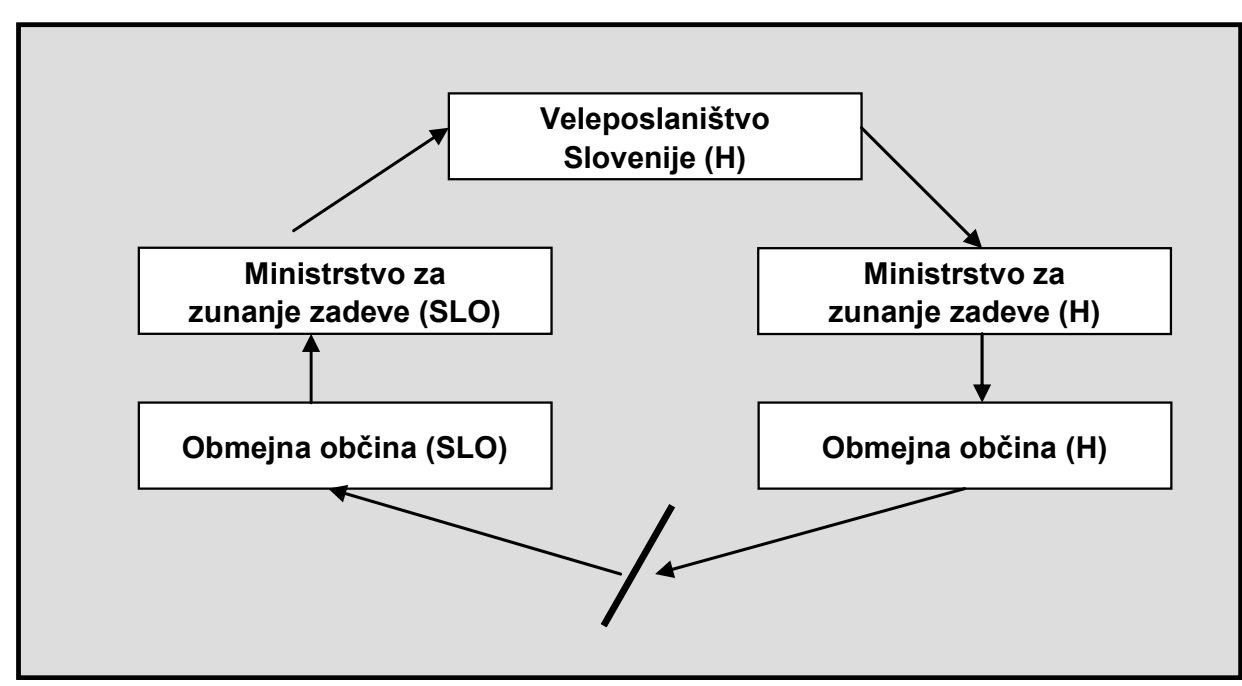

*V primeru sodelovanja slovenske občine z avstrijsko je na avstrijski strani med ministrstvom za zunanje zadeve in občino še deželna raven, $v$ katere pristojnost $v$ Avstriji sodi lokalna samouprava

Sodelovanje slovenskih, madžarskih in avstrijskih občin bi v dobršni meri lahko olajšali meddržavni sporazumi o čezmejnem sodelovanju lokalnih skupnosti $v$ skladu z madridsko konvencijo. Ti sporazumi (ali en tripartitni) bi med drugim zavezali vse tri države podpisnice $k$ hitrem razreševanju problemov, ki ovirajo sodelovanje občin ob tromeji, k obveščanju drugih podpisnic o vseh sistemskih spremembah, ki bi utegnile vplivati na čezmejno sodelovanje občin, k ustanovitvi posebne komisije, ki bi spremljala čezmejno sodelovanje lokalnih skupnosti in $\mathrm{k}$ določitvi morebitnih območij, ki jih bodo države podpisnice še posebej skrbno spremljale. 
Roman Lavtar

Medobčinsko sodelovanje kot mehanizem celostnega

Upravljanja razvoja in vstopanja $v$ čezmejna sodelovanja

Kadar sporazumov o čezmejnem sodelovanju lokalnih skupnosti ni - ne glede na to, da so vse države, ki jih stvar zadeva članice Evropske unije - je čezmejno sodelovanje lahko bolj okorno. Kot utemeljitev pomembnosti meddržavnih sporazumov navajamo sporazum o čezmejnem sodelovanju lokalnih skupnosti, ki ga pripravljata Španija in Portugalska, ki sta dolgoletni članici $\mathrm{EU}^{\mathbf{1 2}}$. Razlog za to je prav gotovo na eni strani $v$ spoznanju o pomembnosti čezmejnega sodelovanja lokalnih skupnosti in na drugi strani v dejstvu, da sodi lokalna samouprava tudi po institucionalnih spremembah $\vee$ Evropi $\vee$ pristojnost nacionalnih držav in ne Bruslja.

Ne občina ne zveza občin pri čezmejnem sodelovanju seveda ne more prevzemati obveznosti, ki bi bremenila državo. V kolikor bi čezmejno sodelovanje naletelo na zakonske ali druge ovire, ki zadevajo pristojnosti vlade, pa bi se $\checkmark$ reševanje lahko vključili vladi obeh (ali treh) držav. Zveza občin bi tudi v tem pogledu lahko zmanjšala ovire, še posebej pri usklajevanju medsebojnih interesov občin in pri iskanju lastnih koristi čezmejnega sodelovanja, predvsem pa bi odločitve sprejemala hitreje.

\subsection{Evroregija kot oblika čezmejnega sodelovanja}

Evroregije kot oblika čezmejnega sodelovanja so se pojavile po letu 1990. Ustanovitelji oziroma partnerji v okviru obstoječih evroregij so se odločali glede oblike sodelovanja upoštevajoč pristojnosti, ki jih imajo partnerske regije. Regionalne skupnosti $v$ različnih državah imajo različne pristojnosti. Zaradi tega je bilo sodelovanje $v$ okviru evroregije praviloma omejeno na najmanjši skupni imenovalec oziroma na tisto možno raven, ki omogoča vsem sodelujočim izvajanje lastnih pristojnosti, odvisno od vrste vanjo vključenih subjektov. To dejstvo vsekakor lahko ovira sodelovanje med partnerji npr. pri razvoju skupnih projektov znotraj evroregije.

Pregled tipologije čezmejnih struktur za pospeševanje razvoja, ki presegajo zgolj medobčinsko sodelovanje, pokaže tri glavne oblike čezmejnih večnamenskih struktur in sicer evroregijo, delovno skupnost ter specifično strukturo za Interreg EU. Evroregija je čezmejna struktura trajnega in strateškega značaja, ki ima svojo lastno identiteto, ki je različna od njenih članic - je (lahko) pravna oseba, ima svoje lastne administrativne, tehnične in finančne vire in ima sistem svojega lastnega internega odločanja. Ima svoj upravni odbor, katerega člani so najvišji voljeni predstavniki oblasti konstitutivnih članic evroregije (predsedniki, glavarji, župani, guvernerji, predsedniki manjšinskih organizacij). Na primer, delovna skupnost Alpe Jadran je čezmejna struktura trajnega značaja, navadno

12 Vir Svet Evrope, pregled stanja na področju aktivnosti držav članic, CDLR (2004) 46 


\section{Roman Lavtar \\ Medobčinsko sodelovanje kot mehanizem celostnega Upravljanja razvoja in vstopanja $v$ čezmejna sodelovanja}

nima lastne pravne subjektivitete - ohrani identiteto svojih članic, nima svojih lastnih finančnih in kadrovskih virov, deluje na podlagi izmeničnega predsedovanja, sekretariata in delovnih skupin, kjer se občasno srečujejo predstavniki članic. Specifična čezmejna struktura, pomembna za slovenske lokalne skupnosti, je program Interreg EU, ki je bil vzpostavljen za uvajanje Interregovih in drugih evropskih programov oziroma pobud. To je predvsem operativna struktura. Ima skupen nadzorni programski odbor in sekretariat. Organ upravljanja za pobudo EU Interreg IIIC - Slovenija - Madžarska - Hrvaška je Agencija RS za regionalni razvoj. Nas zanimata predvsem prvi dve obliki, ki ju je mogoče razumeti tudi kot dve razvojni fazi istega povezovanja, saj konkretni primeri dlje časa delujočih evroregij kažejo, da na začetku delujejo kot delovne skupnosti, šele $\vee$ zrelem obdobju se ustanovitelji odločajo za trdnejše institucionalne povezave.

Organizacijske strukture evroregij se med seboj razlikujejo, najbolj razvite imajo oblikovana dva organa. Prvi je upravni odbor evroregije, uprava evroregije, (Executive of trust, Vorstand, le Comite directeur), ki je najvišji organ odločanja. Sestavljajo ga najvišji voljeni predstavniki regij, provinc, lokalnih enot in manjšin. Drugi je Svet evroregije (Council of euroregion, Euregiorat, Conseil euregional), katerega naloge so predvsem priprava predlogov za čezmejno sodelovanje, predlogov za razne skupne aktivnosti, priprava programov in dajanje zaključnih mnenj k izboru projektov. Sestavljajo ga predstavniki raznih interesnih združenj, političnih strank, nevladnih organizacij, gospodarskih, obrtnih, kmetijskih, industrijskih in trgovinskih zbornic, predstavniki univerz, sindikatov, delodajalcev ipd. Svetu v pomoč je lahko organiziranih več komisij kot specializiranih posvetovalnih teles (za gospodarska vprašanja, okolje, kulturo, itd).

Spričo vse pogostejših pojavnih oblik t.i. evroregije Svet Evrope že dlje časa pripravlja v našem prispevku že omenjeni tretji protokol k Evropski okvirni konvenciji o čezmejnem sodelovanju teritorialnih skupnosti in oblasti, ki jo pogosto zaradi kraja podpisa imenujejo madridska ${ }^{\mathbf{1 3}}$. Tretji protokol naj bi ponudil državam nove pravne okvire prav za delovanje evroregij. Danes delujoče evroregije imajo zelo različne pravne temelje in upravljavske strukture ter področje delovanja. Skupno jim je le to, da pospešujejo čezmejno sodelovanje, ki sega širše od čezmejnega sodelovanja občin in pogosto zajema regionalne strukture več kot dveh držav. Pojem »evroregija " označuje vsa tista bolj ali manj formalizirana telesa, ustanovljena za pospeševanje čezmejnega sodelovanja občin in regij iz različnih držav, ki zajema področja pristojnosti in delovanja občin in regij, ki so $v$ tako entiteto vključena. Nekatera od teh teles, označena s pojmom »evroregi-

13 Ob 25. obletnici Evropske okvirne konvencije o čezmejnem sodelovanju teritorialnih skupnosti, Varšava, 21. - 22. april 2005, Poročilo Yvesa Lejeuneja, Dokument CDLR (2005) 26, Strasbourg, 18. maj 2005 
Roman Lavtar

Medobčinsko sodelovanje kot mehanizem celostnega

Upravljanja razvoja in vstopanja $v$ čezmejna sodelovanja

ja«, so zgolj posvetovalna in pomenijo način koordinacije aktivnosti na določenih področjih s ciljem doseganja zastavljenih skupnih razvojnih ciljev širšega območja, ki sega preko meja ene same države. Ta posvetovalna telesa nimajo opredeljenega pravnega statusa. Druga imajo opredeljen pravni status pravne osebe zasebnega prava in imajo možnost operativno prispevati k regionalnemu razvoju med drugim tudi s pripravo skupnih razvojnih projektov in kandidiranjem za sredstva evropskih strukturnih skladov. Ta oblika evroregije ima tudi bolj formalizirano in strukturirano upravljavsko strukturo in pooblastilo ustanoviteljic, da sprejema odločitve.

Cilj tretjega protokola k madridski konvenciji je:

- pripraviti splošen pravni instrument, ki bi državam omogočal, da občinam in regijam ponudijo standardizirane pravne rešitve $v$ obliki evroregionalnih skupin za sodelovanje (Euroregional Co-operation Groupings, EGCs),

- vzpostaviti enotna pravila igre, sprejemljiva za vse države članice Sveta Evrope, ki bi temeljila na skupnih principih, skladnih z ustavno ureditvijo vseh držav članic,

- omogočiti, da bi bil ta pravni instrument uporabljiv kolikor je mogoče neposredno ne glede na specifične pravne ureditve $v$ državah članicah in

- dati tem pravilom obliko pravnega instrumenta z močjo in veljavo, ki bi jih občine in regije uporabljale $v$ vseh državah članicah.

Gre seveda za neobvezen pravni instrument, ki ga bodo evroregije lahko uporabile ali pa tudi ne. Če pa ga bodo, ga bodo uporabljale $v$ kombinaciji $z$ nacionalno zakonodajo držav, na področju katerih je evroregija oblikovana. Za njeno delovanje bodo veljala tudi določila o obliki, delovanju kot tudi nadzoru nad delovanjem evroregije notranje zakonodaje države, $v$ kateri bo določen sedež evroregije. Tak pravni status bodo priznale tudi druge pogodbene države, se pravi države iz katerih se lokalne in regionalne skupnosti vključujejo v evroregijo.

Vsebina pravnega instrumenta, o katerem govorimo, bi vsebovala nekatera osnovna pravila kot na primer osnovna določila statuta, organe upravljanja evroregije, pristojnosti, ki bi jih države prenesle na evroregijo (v kolikor bi šlo za to, da bi evroregija opravljala naloge oziroma pristojnosti države, bi bilo to pravno potrebno urediti tudi z nacionalno zakonodaja držav, vključenih $v$ omenjene povezave), neprofitni status, osnovna finančna in proračunska pravila, sodelovanje zasebnih in nevladnih organizacij, morebitni vpis $v$ register itd. 


\section{Roman Lavtar \\ Medobčinsko sodelovanje kot mehanizem celostnega Upravljanja razvoja in vstopanja $v$ čezmejna sodelovanja}

Da gre $v$ primeru čezmejnega sodelovanja, torej tudi evroregij, za resno napredujoč političen projekt, kaže tudi dejstvo, da poleg Sveta Evrope tudi Evropska unija pripravlja poseben dokument, s katerim naj bi uredili možnost bolj organiziranega nastopa čezmejnih povezav znotraj institucionalne strukture EU. Komisija in parlament tako obravnavata uredbo o ustanovitvi Evropskih skupnosti za čezmejno sodelovanje (European Grouping of Cross-border Co-operation, EGCC). ${ }^{14}$ Ta razširja možnosti čezmejnega organiziranja predvsem $v$ statusno pravnem vidiku, konkretizacijo oblik pa prepušča zainteresiranim stranem samim. Evropska komisija je predlog uredbe oblikovala na temelju predloga za oblikovanje novega cilja 3 (teritorialno sodelovanje) in na podlagi predloga za uredbo, ki ureja splošne predpise za strukturne in kohezijski sklad. Predlog uredbe Evropske komisije za ustanovitev takšne evropske skupnosti za čezmejno sodelovanje (evroregije) sicer predvideva predhodno dovoljenje matične države, ko pa je takšna skupnost formirana, je matična država ne more več ukiniti. Zato je razumljivo, da nekatere države članice EU npr. Nizozemska, ki imajo dolgoletno tradicijo na področju čezmejnega sodelovanja, takšnemu predlogu uredbe nasprotujejo, ker po njihovem mnenju država izgubi nadzor nad procesom.

\subsection{Zveza občin in trideželni krajinski park}

Domneva, da je javni zavod Krajinski park Goričko institucionalen predstavnik pomurskih lokalnih skupnosti pri ustanovitvi in upravljanju trideželnega krajinskega parka, je zmotna. Zavod ima po svoji naravi specifične in specializirane naloge, ki pa ne predstavljajo splošnih interesov prebivalcev. Legitimni predstavniki slednjih so občine. Kot smo že ugotovili, je interese več različnih občin težko usklajevati brez trajnejše institucionalne strukture. Zato je ena od možnosti ustanovitev zveze občin. In če jo občine ustanovijo, bodo organi zveze lahko legitimni predstavnik občin pri pogajanjih in usklajevanjih interesov tako znotraj Krajinskega parka Goričko kot tudi pri uveljavljanju interesov slovenskih lokalnih skupnosti v trideželnem parku, ki bi lahko deloval ne le kot oblika sodelovanja treh krajinskih parkov, pač pa kot način usklajevanja razvojnih načrtov občin iz treh držav na tromeji.

14 Proposal for a Regulation of the European Parliament and of the Council establishing a European Grouping of Cross-border Co-operation, EGCC, doc. COM (2004) 496 final - COD 2004/0168, Brussels, 23 July 2004 


\section{Roman Lavtar}

\section{Medobčinsko sodelovanje kot mehanizem celostnega \\ Upravljanja razvoja in vstopanja v čezmejna sodelovanja}

Osnutek sporazuma ${ }^{15}$, ki je bil pripravljen v okviru projekta Krajinski park Goričko, čeprav osredotočen zgolj na bodoče območje trideželnega parka, je dobra osnova za pospešitev procesov čezmejnega sporazumevanja in dogovarjanja, vendar zadeva le okvir delovanja prihodnjega parka, ne pa celostnega razvoja in upravljanja omenjenega območja. Omenjeni osnutek zato kljub navedbi v naslovu nima narave "meddržavnega dokumenta, saj naj bi ga podpisali predstavniki vseh treh parkov, ne pa predstavniki vlad. Zato bo dogovor zavezoval zgolj vodstva vseh treh parkov, ne pa tudi predstavnikov vlad in občin, ki so nosilci pooblastil za vse pomembne odločitve tudi za park. Ne glede na svetle cilje, ki jih zasledujejo vodstva treh parkov, so prostorsko načrtovanje, gospodarski razvoj, varovanje okolja ter morebitna investicijska sredstva $v$ najzahtevnejše infrastrukturne projekte na območju parkov $\vee$ domeni bodisi občin in bodisi vlad (deželnih $\checkmark$ Avstriji ali državnih na Madžarskem in v Sloveniji). S tem ne želimo zmanjšati pomena povezovanja dejavnosti treh parkov, jasno pa se moramo zavedati dejstva, da mora biti omenjeno povezovanje, če želi biti zares učinkovito, le predhodnica nekega resnejšega povezovanja institucionalnih struktur občin iz vseh treh držav. Poenostavljeno zapisano: dogovor o sodelovanju treh parkov bi lahko postal ogrodje, na katerem bi nastala prava evroregija.

Izkušnje mnogih krajinskih parkov ali evroregij, ki segajo čez meje držav, kažejo, da sprva sodelovanje temelji na zelo neformaliziranih oblikah. Zato tudi $\checkmark$ našem primeru ni nujno takoj razmišljati o bolj ali manj razvejani institucionalni upravljavski strukturi trideželnega parka. $V$ prvi fazi je treba na slovenski strani predvsem organizirati skupno telo, ki bo imelo pooblastila za dogovore z odgovornimi institucijami z avstrijske in madžarske strani. Po vzoru na že delujoče primere na tromeji med Belgijo, Nizozemsko in Nemčijo ${ }^{\mathbf{1 6}}$ je spodaj predstavljen predlog sheme organizacijske infrastrukture delovanja bodočega trideželnega parka, v kolikor bo do njegove ustanovitve prišlo.

Pri tem je potrebno upoštevati različne okoliščine, ki za delovanje lokalne samouprave veljajo $v$ treh državah. Omejitev pristojnosti občine pri mednarodnem sodelovanju smo že omenili. Poleg tega je lahko ovira tudi dejstvo, da imajo tri države poleg različnih nalog in pristojnosti občin (na Madžarskem imajo občine nekaj manj pristojnosti v primerjavi s slovenskimi in avstrijskimi) tudi različno nivojsko organizirano lokalno samoupravo. Medtem, ko imata Slovenija in Madžar-

15 Razvoj skupnega naravnega parka v Pomurju (PHARE čezmejno sodelovanje SLO/MADŽ) - Končno poročilo, Priloga 8: Osnutek meddržavnega sporazuma med Krajinskim parkom Goričko, Nemzeti Parkom Örseg in Naturpark Raab, vir Ministrstvo za okolje in prostor.

16 Entwiklungsperspektive Dreilanderpark, Offener Raum ohne Grenzen, Projektna skupina, Nizozemska (Maastricht-Heerlen/Hasselt-Aachen-Liege), www.sos-project.org 
ska le enonivojsko lokalno samoupravo (občine), ima Avstrija dvonivojsko (občine in dežele).

Slika 3: Predlog organizacijske sheme za upravljanje euroregije trideželni park

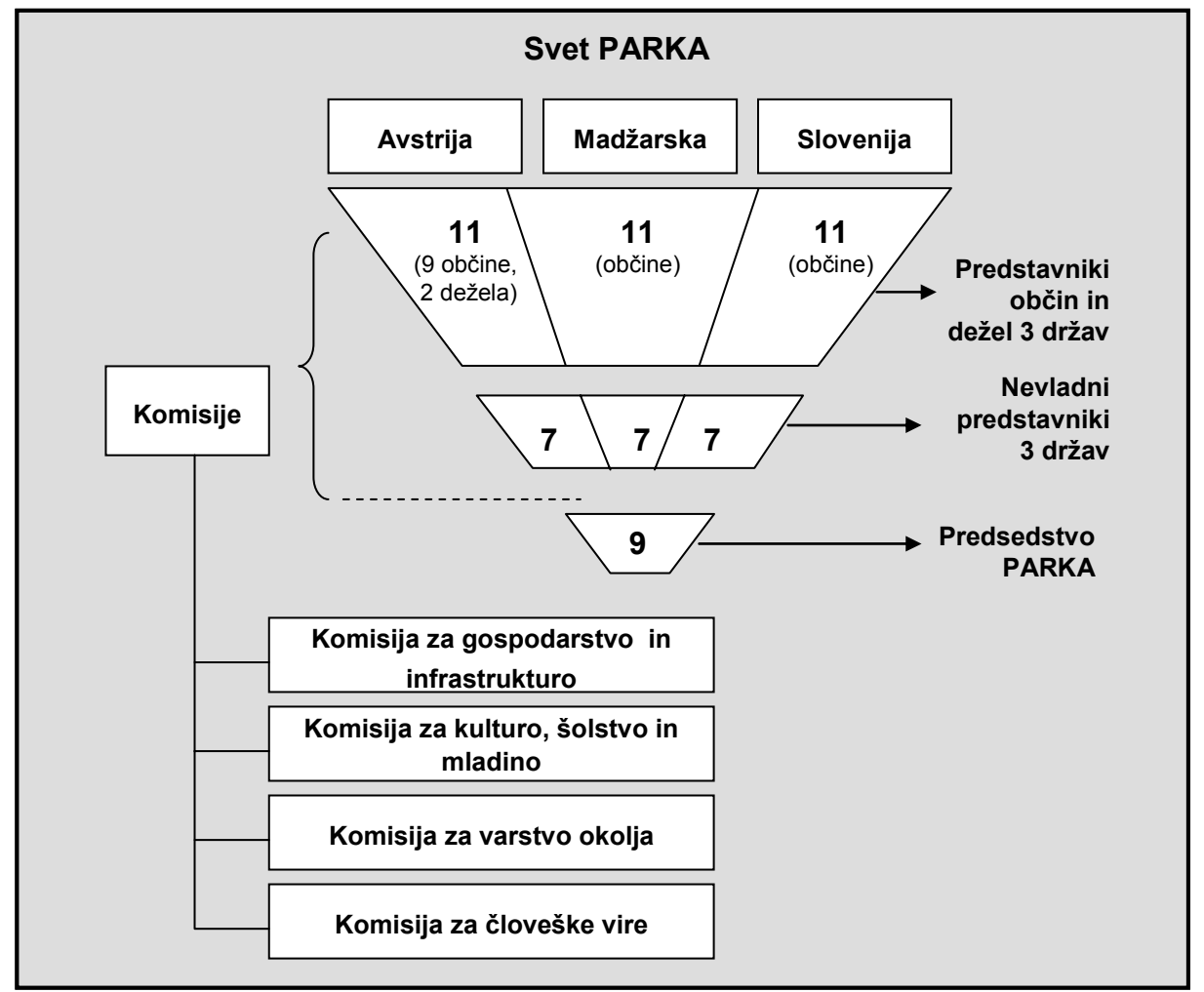

Organiziranost upravljanja trideželnega parka temelji na nekaterih tujih vzorih", vendar je prilagojena na konkretne razmere, zato se utegne še spremeniti. Da je političnih predstavnikov občin in dežele iz vsake države prav enajst, ni naključje, saj je na slovenski strani vključenih enajst občin. $V$ kolikor bo to število zaradi manjših stroškov manjše, bo zveza občin s slovenske strani predlagala manj predstavnikov. Avstrija ima še dodaten problem, ker se bo $v$ upravljanje parka morala vključiti tudi deželna raven, toda njihovi predstavniki si bodo kvoto morali razdeliti s predstavniki avstrijskih občin. Občine bodo morale pozvati predstavnike nevladnih organizacij, da predlagajo kandidate $\vee$ svet parka. Svet parka naj bi imel tudi predsedstvo s tremi predstavniki iz vsake države.

17 Gre za tri primere z belgijsko-nizozemsko- nemške tromeje in sicer Euregio Maas - Rhein, Park treh dežel, Provinca Limburg in MHAL Region. 
Roman Lavtar

Medobčinsko sodelovanje kot mehanizem celostnega

Upravljanja razvoja in vstopanja $v$ čezmejna sodelovanja

Ker projektov zaradi prevelikega števila članov ne bo mogoče obravnavati na svetu, bo ta moral ustanoviti več komisij, ki naj bi bile kot posvetovalna telesa sveta prav tako sestavljene izmed članov sveta, predstavnikov občin in dežel na eni in predstavnikov nevladnih organizacij na drugi strani. Ali so predlagane komisije prave ali ne, bodo seveda odločil člani sveta trideželnega parka. Ker gre za prostovoljno interesno združevanje, imajo predlagani organi zgolj posvetovalno vlogo. Tako svet kot tudi komisije naj bi bila posvetovalna telesa, ki ne bi sprejemala operativnih odločitev. Za operativno vodenje aktivnosti $v$ parku bi lahko ustanovili poseben tričlanski direktorski odbor, ki bi se odločal na podlagi razprav in zaključkov sveta parka. Imeti bi moral minimalno administrativno podporo, sestajal pa bi se vsakič $v$ drugi državi.

Formalne odločitve, ki zadevajo prostorsko načrtovanje in odločanje, povezano $z$ na primer vlaganji $v$ javno infrastrukturo, ter skupni nastop pri kandidiranju za sredstva evropskih strukturnih skladov, bi seveda še naprej ostale $\vee$ pristojnosti z notranjo zakonodajo pooblaščenih občinskih ali deželnih organov vsake države. Skratka, občine, zveza občin in dežela (v Avstriji) ne bi z ustanovitvijo posvetovalnih teles trideželnega parka svojih pristojnosti prenesle na prej opisana telesa. Ta bi imela predvsem načrtovalno, posvetovalno in usklajevalno vlogo. Financiranje projektov bi teklo iz že poznanih virov, državnih, deželnih, iz zveze občin in občinskih ter pričakovanih državnih in evropskih. Telesa trideželnega parka torej ne bi nadomestila formalnih predstavniških organov lokalnih in državnih oblasti, pač pa bi bila mesto snovanja skupnih načrtov in usklajevanja interesov lokalnih skupnosti iz vseh treh držav.

\section{Zaključek}

Če želijo lokalne skupnosti pospešiti razvoj, se morajo začeti povezovati. Ideja trideželnega krajinskega parka in že ustanovljeni Krajinski park Goričko ponujata slovenskim občinam in občinam sosednjih držav odlično priložnost in zunanjo spodbudo za skupne projekte. Formalnih ovir za takšno sodelovanje občin ni, če odštejemo odsotnost meddržavnih sporazumov o spodbujanju čezmejnega sodelovanja. Zato imajo slovenske občine $v$ Pomurju in še posebej na Goričkem dobro priložnost, da svoje načrte predstavijo sosedam, jih uskladijo z njimi in z veliko žlico zajamejo razvoj. Z morebitno ustanovitvijo zveze občin za namen skupnega nastopa občin pri načrtovanju razvoja znotraj območja Krajinskega parka Goričko pa bi občine na obstoječo institucionalno strukturo zveze lahko $v$ prihodnje prenesle tudi druge naloge, na primer na področju oskrbe $z$ vodo in odlaganja komunalnih odpadkov ter drugih potreb občin ustanoviteljic. Na obravnavanem konkretnem primeru smo tako $v$ pričujočem prispevku poskušali 


\section{Roman Lavtar \\ Medobčinsko sodelovanje kot mehanizem celostnega Upravljanja razvoja in vstopanja $v$ čezmejna sodelovanja}

pokazati, da pravilno izbran institucionalni model medsebojnega sodelovanja občin, kot je zveza občin, lahko pomembno prispeva k pospešenemu razvoju lokalnih skupnosti in k dvigu ravni čezmejnega sodelovanja.

Roman Lavtar je magister politoloških znanosti, zaposlen v Službi Vlade Republike Slovenije za lokalno samoupravo in regionalno politiko. Doslej je objavil več kot štirideset prispevkov s področja lokalne samouprave $v$ strokovnih in poljudnih revijah. Kot zunanji ekspert je $\checkmark$ letu 2003 sodeloval $v$ projektu Evropske razvojne agencije Reforma javne uprave (PARIM) v Črni gori. Kot zunanji ekspert Združenih narodov (UNDP) je v letih $2004-2005$ sodeloval $v$ projektu zagotavljanja administrativne sposobnosti državne uprave za izvedbo zakonodajne reforme v Črni gori za področje lokalne samouprave. Predava na strokovnih srečanjih s področja javne uprave in lokalne samouprave, na Upravni akademiji Ministrstva za javno upravo, občasno pa tudi na Fakulteti za upravo in Fakulteti za družbene vede Univerze v Ljubljani. V letu 2004 mu je senat Fakultete za upravo podelil naziv višjega predavatelja za področje lokalne samouprave.

\section{Literatura in viri:}

- $\quad$ Citizens as Partners, OECD book on information, consultation and public participation in policy-making, OECD 2001, www.gov.si/svrp/

- $\quad$ EUREGIO Maas - Rhein, www.euregio-mr.org

- Entwicklungsperspektive Dreilanderpark, Offener Raum ohne Grenzen, Projektna skupina, - Nizozemska (Maastricht-Heerlen/Hasselt-Aachen-Liege), www.sos-project.org

- Gotovac, J, (2005): Ustanovitev interesne zveze občin, Strokovni posvet Občine v celostnem upravljanju Krajinskega parka Goričko, Grad, 20.april 2005

- Lavtar, R.: Primer uspešne regionalizacije, Reforma lokalne samouprave na Češkem, Slovenska uprava, str. 32-33, izd. Ministrstvo za notranje zadeve, štev.3, letnik 4, Ljubljana

- Structure and operation of local and regional democracy, France, Council of Europe, Strassbourg

- Proposal for a Regulation of the European Parliament and of the Council establishing a European Grouping of Cross-border Co-operation, EGCC, doc. COM (2004) 496 finalCOD 2004/0168, Brussels, 23 July 2004

- Priporočilo Rec (2001) 19 Ministrskega odbora državam članicam o sodelovanju državljanov pri lokalnem javnem življenju, sprejeto 6.decembra 2001

- Priročnik o čezmejnem sodelovanju Sveta Evrope, www.gov.si/svrp/

- Strategija razvoja Slovenije (2005), Vlada Republike Slovenije, Ljubljana, 


\section{Roman Lavtar}

\section{Medobčinsko sodelovanje kot mehanizem celostnega}

Upravljanja razvoja in vstopanja v čezmejna sodelovanja

- Uredba o Krajinskem parku Goričko, Uradni list RS štev. 101/2003

- Razvoj skupnega naravnega parka v Pomurju (PHARE čezmejno sodelovanje SLO/MADŽ) - Končno poročilo, Priloga 8: Osnutek meddržavnega sporazuma med Krajinskim parkom Goričko, Nemzeti Parkom Örseg in Naturpark Raab, vir Ministrstvo za okolje in prostor

- Razvoj skupnega naravnega parka v Pomurju, PHARE čezmejno sodelovanje Slovenija Madžarska, Končno poročilo projekta štev. SI.00.08.01, september 2003

- Zakon o lokalni samoupravi (ZLS) (Uradni list Republike Slovenije 72/93, 57/94, 14/95, 63/95-obvezna razlaga, 26/97, 70/97, 10/98, 74/98, 70/00, 51/02) in odločitve ustavnega sodišča objavljene v Uradnem listu RS 6/94, 45/94, 20/95, 9/96, 39/96, 44/96,59/99, 108/03)

- Zakon o ratifikaciji Evropske listine lokalne samouprave (MELLS) - Uradni list RS-MP št. $15 / 1996$

- Zakon o ratifikaciji Evropske okvirne konvencije o čezmejnem sodelovanju teritorialnih skupnosti ali oblasti (MEOKčS) (Uradni list RS, št. 8/03)

- Zakon o ohranjanju narave, Uradni list RS št.22/03 - UPB1) 


\section{SUMMARY \\ Inter-municipal Co-operation as a Mechanism of Integrated Management of Development and Entering Into Cross-Border Co-operation}

This paper deals with the establishment of an association of municipalities as a driving force for improved inter-municipal co-operation in the realisation of development needs of municipalities; or, in other words, as a means of representing the interests of several municipalities in the performance of public services on the one hand, and as a means of integrating a group of municipalities into cross-border co-operation on the other. Inter-municipal co-operation is becoming a necessary factor for the development of Slovenian municipalities. Enclosure within one's own borders does not contribute to the solving of municipal issues; moreover it renders them more complex or in turn creates new ones. This holds particularly true for border municipalities. Slovenian legislation offers a variety of legal and formal opportunities for inter-municipal co-operation. The legislation opens up opportunities for co-operation in the performance of municipal administrative tasks and the implementation of public services, both economic and non-economic in nature. For the purposes of a more effective presentation, this paper attempts to present, on the basis of concrete examples for eleven municipalities in the Pomurje region, the benefits of establishing an association of municipalities as a formal construction for more efficient co-operation in the management of the Goričko Landscape Park and the management of the future trilateral park in co-operation with local communities on the other side of the border in Austria and Hungary, taking into account potential opportunities for the establishment of an Euro-region in this territory.

A comparison of the tasks and powers of Slovenian municipalities according to size shows that the size of Slovenian municipalities is not optimal, which is further evidenced by the economic criterion of rationality. A more detailed analysis of the operation of joint municipal administration bodies and the realisation of founders' rights through joint administration bodies shows that these forms are not adequate for the efficient performance of inter-municipal co-operation, making it necessary to design inter-municipal co-operation on the basis of another legal form. 
Roman Lavtar

Medobčinsko sodelovanje kot mehanizem celostnega

Upravljanja razvoja in vstopanja v čezmejna sodelovanja

It is necessary to establish an interest group of municipalities which is not a local community or an institution above the municipality, but a mechanism for the joint performance of municipal tasks. The association of municipalities differs from other forms of co-operation by virtue of the fact that in this case, we are dealing with a new independent legal person of public law which has established an association council for management purposes. The association as an organisational and legal form is well suited for the implementing of joint long-term projects which go beyond municipal boundaries.

Participation of inhabitants in decision-making related to public affairs at the local level is important in enhancing confidence in local authorities and the level of legitimacy of local authorities. It is therefore advisable to include the representatives of local inhabitants and non-governmental organisations who have not been elected to municipal councils of municipalities which are the founding partners of an association of municipalities in the functioning of municipalities and inter-municipal cooperation, management structures or the decision-making process. A consultative body, in which representatives of environmental and interest groups are included, must be established when establishing an association of municipalities.

Through the potential establishment of an association of municipalities for the purpose of joint action in development planning within the territory of the Goričko Landscape Park, the municipalities could also transfer other tasks to the existing institutional structure of the association in the future, such as those related to water supply and waste disposal and other needs of the municipalities that are the founding partners. This paper thus attempts to show, using the concrete example in question, that a correctly chosen institutional model of inter-municipal co-operation, such as an association of municipalities, can contribute significantly to an accelerated development of local communities and an increase in cross-border co-operation. The establishment of the Goričko Landscape Park has re-opened the issue of the manner of integration of municipalities in the process of long-term development of the wider region of Pomurje. The municipalities concerned should therefore take care of the promotion of their interests related to the economic development and conservation of natural and cultural heritage and the harmonisation of their interests with the interests of other municipalities within the Park area. The management of such a complex project as the sustainable and 
economic development of a good half of the entire Pomurje region requires close inter-municipal co-operation, therefore some more consideration of the idea of an association of municipalities is undoubtedly justified. If this association is eventually established, the bodies of this association will be legitimate representatives of municipalities in the negotiations and co-ordination of interests both within the Goričko Landscape Park and when promoting the interests of Slovenian local communities in the three-state park, which could operate not only as a means of co-operation between the three parks but also as a means for co-ordinating development plans of municipalities from the three bordering countries. We have to bear in mind the fact that the abovementioned integration - if it strives to be really effective - is only a predecessor of a more intensive integration of municipal institutional structures from all three countries; a co-operation agreement concluded between the three parks could come to serve as a framework for a true Euro-region.

Local communities have been encountering problems as long as state borders have existed. Limited movement, increasingly complicated everyday problems of inhabitants and the limited rights of local communities in everyday co-operation represent a source of serious issues for local communities. In the absence of agreements on cross-border co-operation - irrespective of the fact that all countries concerned are also EU member states - cross-border co-operation can be hindered to some extent. Euroregions, as a means of cross-border co-operation, originated after 1990. The founding partners or partners within the framework of the existing regions have adopted decisions based on various forms of co-operation, taking into account the powers of partnership regions. Regional communities have different powers in different countries. This is why cooperation within the framework of one Euro-region was limited to the smallest common denominator or to that level whereby all participants are able to implement their own powers, depending on the nature of the subjects involved. Given the increased occurrence of forms of the socalled Euro-region the Council of Europe has been preparing the third protocol to the European Framework Convention on cross-border cooperation of territorial communities and authorities, already mentioned in the present paper, and often referred to as the Madrid Convention due to the place of its signature. Cross-border co-operation, and therefore also Euro-regions, is a political project that is increasingly gaining in importance, evidenced by the fact that apart from the Council of Europe, the European Union too is drawing up a document which should enable a 
Roman Lavtar

Medobčinsko sodelovanje kot mehanizem celostnega

Upravljanja razvoja in vstopanja $v$ čezmejna sodelovanja

more organised establishment of cross-border integrations within the EU institutional structure.

The experience of numerous landscape parks or Euro-regions extending across state borders shows that co-operation is initially based on very informal forms. Therefore, likewise in our case it is not necessary to consider a more or less institutionally ramified management structure of the three-state park. What needs to be done in the first phase in Slovenia is primarily to establish a joint body which will have powers to conclude agreements with competent institutions in Austria and Hungary. Upon the establishment of consultative bodies, municipalities, the association of municipalities and federal states (in Austria) would not transfer their powers to the newly established bodies. These would have, above all, a planning, consultative and co-ordinating role. Project funding would be carried out from previously identified sources, state, federal, municipal association and municipal funds, and of course, the expected state and European funds. The bodies of the three-state park would thus not replace formal representative bodies of local and state authorities, but would instead represent a place for designing joint plans and the co-ordination of local community interests from all three countries. 